\title{
MÃES E PAIS DO MÉTODO CANGURU: DESAFIOS DE GESTAR DURANTE A PANDEMIA DA COVID-19
}

\section{ARTIGO ORIGINAL}

KAZANOWSKI, Juliana ${ }^{1}$, SARAIVA, Thakacki Cézar de Oliveira ${ }^{2}$, LUCENA, Larissa Sena de ${ }^{3}$, SOARES, Nathália Jolly Araújo ${ }^{4}$, MELO, Priscila Kesla Fonseca Sousa ${ }^{5}$, NEVES, Maribel Nazaré dos Santos Smith ${ }^{6}$, FECURY, Amanda Alves ${ }^{7}$

KAZANOWSKI, Juliana. Et al. Mães e pais do método canguru: desafios de gestar durante a pandemia da Covid-19. Revista Científica Multidisciplinar Núcleo do Conhecimento. Ano. 07, Ed. 01, Vol. 06, pp. 106-122. Janeiro de 2022. ISSN: 24480959, Link de acesso: https://www.nucleodoconhecimento.com.br/saude/desafios-degestar

\section{RESUMO}

Introdução: Os genitores de recém-nascidos a partir do ano de 2020 vivenciaram a gestação durante a pandemia da Covid-19, período em que as incertezas foram evidentes no mundo todo. Ademais, o processo de gestar por si só é um período crítico e torna-se mais desafiador ao estar aliado a prematuridade e baixo peso como vivenciados pelos pais e mães do Método Canguru. Visando entender este processo o presente trabalho teve como pergunta norteadora: Como está sendo a experiência

\footnotetext{
${ }^{1}$ Graduanda. ORCID: https://orcid.org/0000-0001-9117-4783

${ }^{2}$ Graduação. ORCID: https://orcid.org/0000-0003-3449-2608

${ }^{3}$ Graduanda. ORCID: https://orcid.org/0000-0002-0607-3417

${ }^{4}$ Graduação e Residente em Pediatria. ORCID: http://orcid.org/0000-0002-0420-2377

5 Graduação e Residente em Pediatria. ORCID: https://orcid.org/0000-0002-65549059
}

${ }^{6}$ Orientador. ORCID: http://orcid.org/0000-0002-1143-4467

${ }^{7}$ Orientador. ORCID: http://orcid.org/0000-0001-5128-8903

RC: 105957

Disponível em: https://www.nucleodoconhecimento.com.br/saude/desafios-de-gestar 
de gestar em tempos de pandemia? Objetivo: Caracterizar o binômio/trinômio de pais e mães das duas primeiras etapas do método canguru em hospital referência do Amapá e compreender suas experiências de gestar durante a pandemia, identificando os principais desafios vivenciados. Método: Estudo do tipo quali-quantitativo e descritivo, realizado através de entrevistas guiadas por questionários e tabulado em planilhas. Foram levantados dados epidemiológicos, como: etapa no método canguru, peso do RN ao nascer, religião, vínculos de moradia, quantidade de consultas prénatal realizadas na gestação e a percepção dos mesmos sobre a gestação em meio a pandemia. Resultados: A maioria dos entrevistados estava na segunda etapa do método, de predominância feminina, de faixa etária de 18-36 anos e recém-nascidos com média de $1.600 \mathrm{~g}$ de peso ao nascer. Os progenitores, em sua maioria, moram juntos, possibilitando uma maior rede de apoio ao RN aliada a predominância da prática cristã e um pré-natal satisfatório, da maioria dos participantes. As principais adversidades vivenciadas foram: a dificuldade para a marcação de consultas e a impossibilidade da participação do cônjuge nas rotinas da gestação devido as modificações nos atendimentos de saúde por conta da pandemia e da precariedade das estruturas de saúde do Estado; o isolamento social com importante impacto na saúde mental e o desenvolvimento de temor do adoecimento em si e em seus recémnascidos. Conclusão: Diante dos dados apresentados definir-se a pandemia da Covid19 como um desafio para a maioria dos entrevistados. Destaca-se que as dificuldades que permearam estas gestações foram a marcação de consultas, a impossibilidade da participação do cônjuge nas rotinas da gestação, o isolamento social e o medo de infecção da doença.

Palavras-chave: Gestação, Pandemia, Covid-19, Método Canguru.

\section{INTRODUÇÃO}

Gestar é uma condição na qual o corpo feminino abriga um ser vivo durante todo o seu processo de desenvolvimento, proporcionando a este as condições necessárias para uma formação que o possibilite estar apto a vida extrauterina após seu 
nascimento. Todavia, o processo de constituição da maternidade vai para além disto, e inicia-se muito antes da concepção, a partir das primeiras relações e identificações da mulher, seguindo pelo período lúdico da infância, criando forma nas experiências da adolescência, e culminando com o desejo de ter um filho e a gravidez propriamente dita. Contribuem também para este processo aspectos transgeracionais e culturais, associados à relação dela com os outros participantes envolvidos neste processo (ARAGÃO, 2006).

Sabe-se, entretanto que o período gestacional é um período crítico para instabilidades emocionais, e diante de todas estas mudanças e vivências psíquicas, a experiência de gestar leva a uma exacerbação da sensibilidade da mulher, o que a torna também suscetível a vários distúrbios emocionais (RAPHAEL-LEFF, 2000). Destaca-se também que, além de todas as mudanças fisiológicas individuais, existem as mudanças que este processo requer no ambiente familiar que espera esse recémnascido (VALANSI; MORSCH, 2004).

Os pais de bebês que nasceram desde o início da pandemia do SARS-CoV-2 vivenciam a gestação, ou parte dela, em pleno período de inseguranças e incertezas. Na metade do mês de abril de 2020, poucos meses depois do início da epidemia em Wuhan, província de Hubei, na China, já havia contabilizado mais de 2 milhões de casos e 120 mil mortes no mundo pelo coronavírus (SARS-CoV-2) (ZHU et al., 2020; WERNECK; CARVALHO, 2020).

Concomitante ao insuficiente conhecimento científico, sua alta velocidade de disseminação e capacidade de provocar mortes em populações vulneráveis, a infecção pelo SARS-CoV-2 gerou fortes incertezas sobre quais seriam as melhores estratégias a serem utilizadas para o enfrentamento da epidemia em diferentes partes do mundo (WERNECK; CARVALHO, 2020). Esta situação foi rapidamente considerada uma Emergência de Saúde Pública de Importância Internacional pela Organização Mundial de Saúde (OMS) e, diante do descontrole do cenário mundial, em 11 de março de 2020 já foi considerada uma pandemia (OMS, 2020). 
O norte do Brasil, já conhecido por suas carências estruturais bem como isolamento geográfico, despertou ainda maiores temores. Já em 15 de maio de 2020, no Estado do Amapá tinham 3.630 casos e 103 óbitos confirmados, apresentando a terceira maior mortalidade pelo vírus da região. Cabe destacar, que esse foi um período de intensa comoção onde as mortes ocorriam sem acompanhamento e sem despedidas tornando o processo de morte e morrer ainda mais sofrido e o medo foi constante (SILVA et al., 2020a). Aliado ao cenário de caos da saúde, foram vivenciados também intensos conflitos sociais.

Polêmicas no mundo das ciências médicas continuam sobre o uso de determinados medicamentos, devido à conotação política atribuída aos medicamentos logo no início; a crise econômica é lembrada todos os dias; o pavor do contágio e da morte nos acompanha nesses tempos difíceis e não sabemos quanto tempo iremos permanecer assim (SILVA et al., 2020a. p. 123).

Diante de tudo isto, é evidente que o processo de gestar neste período foi conturbado e carregado de desafios aos pais, família e toda a rede de apoio deste novo ser sendo gerado. Assim, o gestar em um cenário pandêmico torna-se um desafio importante sendo construídas formas de enfrentamentos particulares vivenciados por cada família neste processo (ROMERO; CASSINO, 2018). As equipes de saúde apresentaram um papel fundamental, tanto durante a consulta do pré-natal ou do puerpério, quanto na atenção hospitalar, pois ter um olhar sensível e a escuta qualificada foi necessária para o atendimento holístico das gestantes neste período requerendo encaminhamentos a equipes multidisciplinares (ESTRELA et al., 2020).

A assistência pré-natal é uma ferramenta, ainda mais importante neste contexto, a qual realiza a classificação de riscos e cuidados de rotina e foram ainda mais necessários neste período, já que a infecção do SARS-CoV-2 na gestante é uma preocupação, pois pode interferir no bom desenvolvimento fetal, sendo responsável por condições de alto risco gestacional, como pré-eclâmpsia, prematuridade, sofrimento fetal e até mesmo a morte perinatal. Condições estas, que necessitam de cuidados especiais ainda durante a gestação (SILVA et al., 2021). 
A morte sempre foi muito temida e estudada, sobretudo na infância, sendo evidenciada fortemente com a pandemia da Covid-19. Dentro os indicadores de saúde de uma população, a taxa de mortalidade infantil é um importante marcador da assistência à saúde prestada, considerando que ela representa mais que a singularidade de um indivíduo, e sim o contexto de ordem socioeconômica e ambiental que ele se insere, incluindo a assistência à saúde materno, assistência ao parto, nascimento e pós-parto. Assim, os cuidados com RNs prematuros, aqueles nascidos antes de completar 37 semanas de idade gestacional, e também de baixo peso (abaixo de $2.500 \mathrm{~g}$ ), já eram uma preocupação mundial por serem fatores condicionantes à mortalidade infantil. Situação esta que encontra apoio técnico através da Política de Atenção Humanizada ao Recém-Nascido de Baixo-Peso Método Canguru (AHRNBP-MC) (DOS SANTOS; OLIVEIRA, 2011).

A criação da AHRNBP-MC, que foi idealizado já em 1979, sendo implantada de forma pioneira, na Colômbia pelo médico Edgar Rey Sanabria e Hector Martinez. No Brasil, esse método teve suas primeiras iniciativas independentes em Santos e em Pernambuco em 1992, tornando-se uma política pública nacional apenas nos anos 2000, por meio da Portaria n 693 de 05 de julho de 2000: Norma de Atenção Humanizada do Recém-nascido Baixo Peso (BRASIL, 2000).

O Método canguru é uma forma de assistência e atenção perinatal voltado para a assistência qualificada e humanizada que reúne estratégias de intervenção biopsicossocial com uma ambiência que favoreça o cuidado ao recém-nascido através dos cuidados institucionais aliados aos cuidados que sua família é ensinada a prover desde os primeiros dias do RN no método. Nesta forma de assistência, o contato pele a pele é de extrema importância, e se inicia o tão precoce possível, como por exemplo através do toque, e evoluindo de forma progressiva até que seja possível e segura a posição canguru (BRASIL, 2018) (BEZERRA et al., 2021).

O método é desenvolvido em sequencialmente por três etapas. A primeira, tem início no pré-natal da gestação que necessita cuidados especializados, durante 0 
parto/nascimento, seguido da internação do recém-nascido na unidade de terapia intensiva neonatal (UTIN) e/ou na unidade de cuidados intermediários neonatais (UCINCo); a segunda etapa é realizada na unidade de cuidados intermediários canguru (UCINCa), de forma a tornar os processos de cuidado, já iniciado na primeira etapa, sólidos com importante atenção ao aleitamento materno; na terceira etapa, os recém-nascidos prematuros e/ou de baixo peso (RNBP) já não estão mais sob os cuidados hospitalares e seguem acompanhados de forma compartilhada pela equipe de saúde tanto no hospital e quanto das equipes da atenção básica treinada para o método canguru (BRASIL, 2018).

Na primeira, relativa à adaptação do Recém-nascido de Baixo Peso (RNBP) a vida extrauterina com grande estímulo da participação da família nos cuidados do bebê, aleitamento materno e contato progressivo pele a pele. A segunda, é direcionada aos RNBP que já podem ficar em uma unidade de cuidados intermediários com a mãe, desfrutando do maior tempo possível da posição canguru, sendo ambos apoiados pela equipe de saúde da unidade. E a terceira, fase domiciliar em que o bebê é acompanhado no ambulatório pela equipe responsável pelo método a cada dois ou três dias inicialmente e depois semanalmente até que atinja $2.500 \mathrm{~g}$ ou mais, após atingir esse peso é encaminhado para puericultura na atenção primária em uma Unidade Básica de Saúde próxima a sua residência (BRASIL, 2018).

No Estado do Amapá o método canguru possui como referência o Hospital Maternidade Mãe Luzia, o qual presta atendimento a todo o Estado e regiões circunvizinhas. Possui em sua estrutura de 78 leitos neonatais cadastrados ao CNES, sendo deles 54 leitos SUS. Estando distribuídos: 6 na Unidade de Cuidados Intermediários Neonatal Canguru (UCINCa), 18 em Unidade de Cuidados Intermediários Neonatal Convencional (UCINCo), 16 Unidade de Terapia Intensiva Neonatal Tipo II (UTINeo) e 14 em especialidade clínica neonatal (BRASIL, 2021). Cabe ressaltar que este hospital é referência terciária para o Ministério da Saúde quanto ao método canguru, bem como para o cuidado neonatal, além de prestar assistência terciária sendo referência no que tange à saúde da mulher. Situa-se em 
Macapá, capital do estado, em uma de suas avenidas principais, endereçando-se na Av. FAB, no 81.

Diante da realidade do método canguru, o presente trabalho tem como pergunta norteadora: Como está sendo a experiência de gestar em tempos de pandemia? Tendo como objetivo caracterizar o binômio/trinômio da população em estudo e compreender suas experiências de gestar durante a pandemia da Covid-19 (SARSCoV-2), identificando os principais desafios vivenciados.

\section{MÉTODO}

O presente estudo é do tipo quali-quantitativo e descritivo. Foi realizado na unidade neonatal do Hospital da Mulher Mãe Luzia (HMML), onde foi aplicado o questionário elaborado pelos pesquisadores e validado previamente, utilizando entrevistas guiadas por questionários estruturados e perguntas abertas realizadas junto aos pais e mães de recém-nascidos internados nas etapas um e dois do método canguru.

A coleta de dados ocorreu por quatro semanas entre os meses de outubro e novembro de 2021. Foram coletados os seguintes dados: idade do entrevistado, etapa no método canguru, peso do $\mathrm{RN}$ ao nascer, religião, vínculos de moradia, quantidade de consultas pré-natal realizadas na gestação e a percepção dos mesmos sobre a gestação em meio a pandemia da Covid-19. E foram inseridos em planilhas do Microsoft Excel 2010 e posteriormente analisados.

Foi estabelecido como critério de inclusão mães e pais serem maiores de 18 anos e como critérios de exclusão pais que convivam com deficiência cognitiva e que apresentassem tempo de convivência na unidade neonatal por um período menor que 7 dias.

Destaca-se que os participantes autorizaram a entrevista mediante a assinatura do Termo de Consentimento Livre e Esclarecido, aprovado pelo Comitê de Ética em Pesquisa CAAE: 48775921.6.0000.0003.

RC: 105957

Disponível em: https://www.nucleodoconhecimento.com.br/saude/desafios-de-gestar 


\section{RESULTADOS}

Dos questionários aplicados para a pesquisa, 22,58\% (7/31) dos entrevistados encontravam-se na primeira etapa do método canguru e 77,41\% (24/31) estavam na segunda etapa. Além disso, foi levantado que $70,96 \%$ (22/31) foram respondidos por mães de $\mathrm{RN}$ e $29,03 \%$ (9/31) pelos pais.

Em relação ao peso ao nascer dos filhos dos entrevistados, obteve-se uma média de $1.590 \mathrm{~g}$ variando de $600 \mathrm{~g}$ até $2.030 \mathrm{~g}$. Sendo distribuídos nas seguintes faixas de peso: $3,23(1 / 31)$ apresentou $<1000 \mathrm{~g}, 9,68 \%$ (3/31) de 1000g a 1299g, 32,26\% (10/31) de $1300 \mathrm{~g}$ a $1599 \mathrm{~g}, 45,16 \%(14 / 31)$ de $1600 \mathrm{~g}$ a $1899 \mathrm{~g}$ e $9,68 \%(3 / 31)>1900 \mathrm{~g}$.

Gráfico 1. Peso ao nascer dos filhos dos entrevistados que participavam do método canguru.

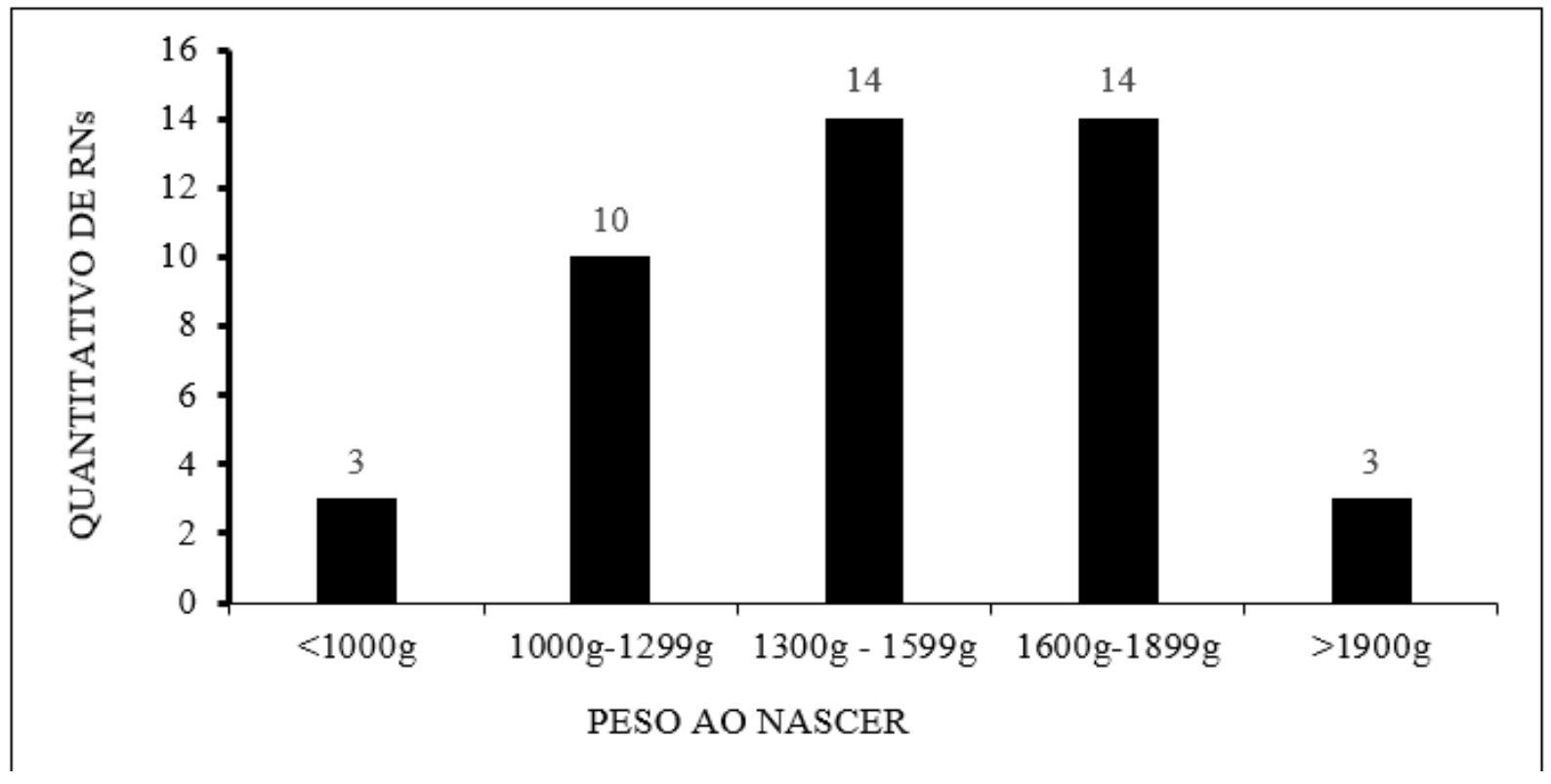

Fonte: Dados próprios.

Os respondentes ao questionário (pai ou mãe) possuíam as mais diversas idades, com média de idade de 28,3 anos. Das mães, 90,9\% (20/22) estava na faixa etária de 18 a 35 anos e 9,09\% (2/22) com mais de 35 anos, já os pais participantes do estudo $44,44 \%$ (4/9) tinham de 18 a 35 anos e 55,56\% (5/9) mais que 35 anos. Levantou-se RC: 105957 
também que dos participantes do método $83,87 \%$ (26/31) moram com o outro progenitor enquanto $16,13 \%$ (5/31) dos progenitores não moram juntos.

Sobre a religião professada pelos participantes da pesquisa, $77,42 \%$ (24/31) responderam que possuem uma religião, enquanto 22,58\% (7/31) referem não ter religião nenhuma. Dos que proferem uma religião 70,83\% (17/24) referiram ser católicos, enquanto 29,17\% (7/24) referiram ser evangélicos. Nenhuma outra religião foi citada nesse estudo.

Sobre as consultas pré-natal dos $\mathrm{RN}$ participantes do método canguru, pode-se perceber conforme o gráfico abaixo que os entrevistados em sua maioria, $64,52 \%$ (20/31), apresentaram um pré-natal adequado, com seis ou mais consultas, conforme preconizado pelo ministério da saúde. Destaca-se que 12,9\% (4/31) dos entrevistados não tiveram assistência pré-natal (Gráfico 2). A pesquisa evidenciou que dos 31 participantes $22,58 \%$ (7/31) relataram que o maior desafio durante a pandemia foi a dificuldade do acesso ao atendimento médico, ressaltando a dificuldade na marcação de consultas como a principal carência. Destes, 25\% (2/8) relataram a dificuldade enfrentada de não poder ter a participação do cônjuge durante as consultas por causa das restrições referentes a aglomeração no consultório. 
Gráfico 2. Número de consultas de pré-natal realizadas durante a pandemia de Covid19 pelos entrevistados.

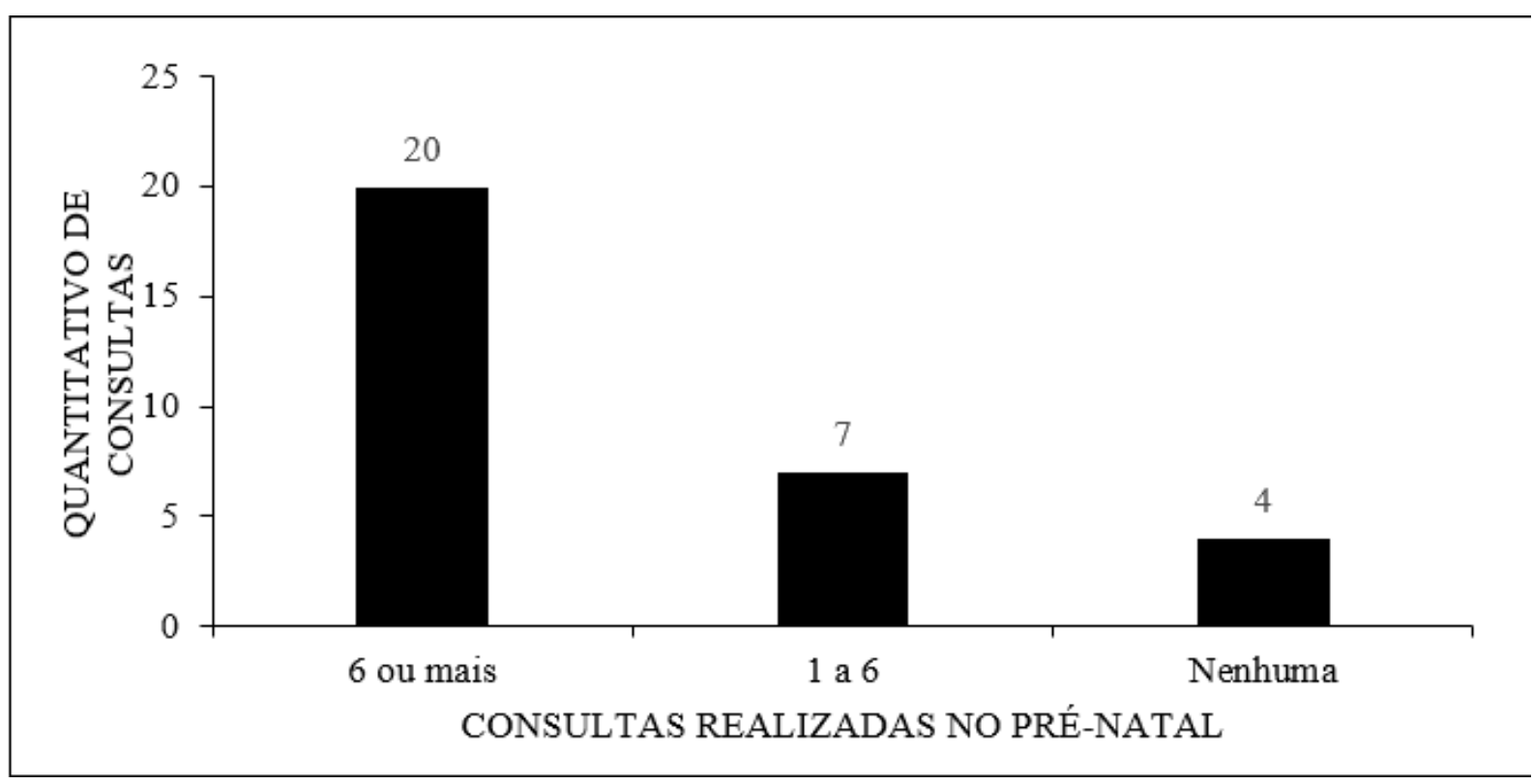

Fonte: Dados próprios.

Sobre gestar durante a pandemia de Covid-19, 77,42\% (24/31) dos participantes relataram que foi difícil ou muito difícil o processo de gestação neste período (Gráfico 3). Dos entrevistados que relataram ser difícil ou muito difícil, 29,17\% (7/24) indicaram o isolamento social como um grande problema a ser enfrentado no momento da gestação em meio a pandemia de Covid-19, e 29,17\%, também relataram que temiam o medo de adoecer ou do bebê nascer doente por causa da pandemia. Dos 22,58\% (7/31) não sentiram dificuldades, ou não perceberam diferença, $57,14 \%$ (4/7) informaram se sentir protegidos ou seguros durante a pandemia, seja por motivo de já estarem vacinados ou por pelo pouco contato com pessoas contaminadas em sua comunidade local. 
Gráfico 3. Dificuldade de gestar durante a pandemia de Covid-19.

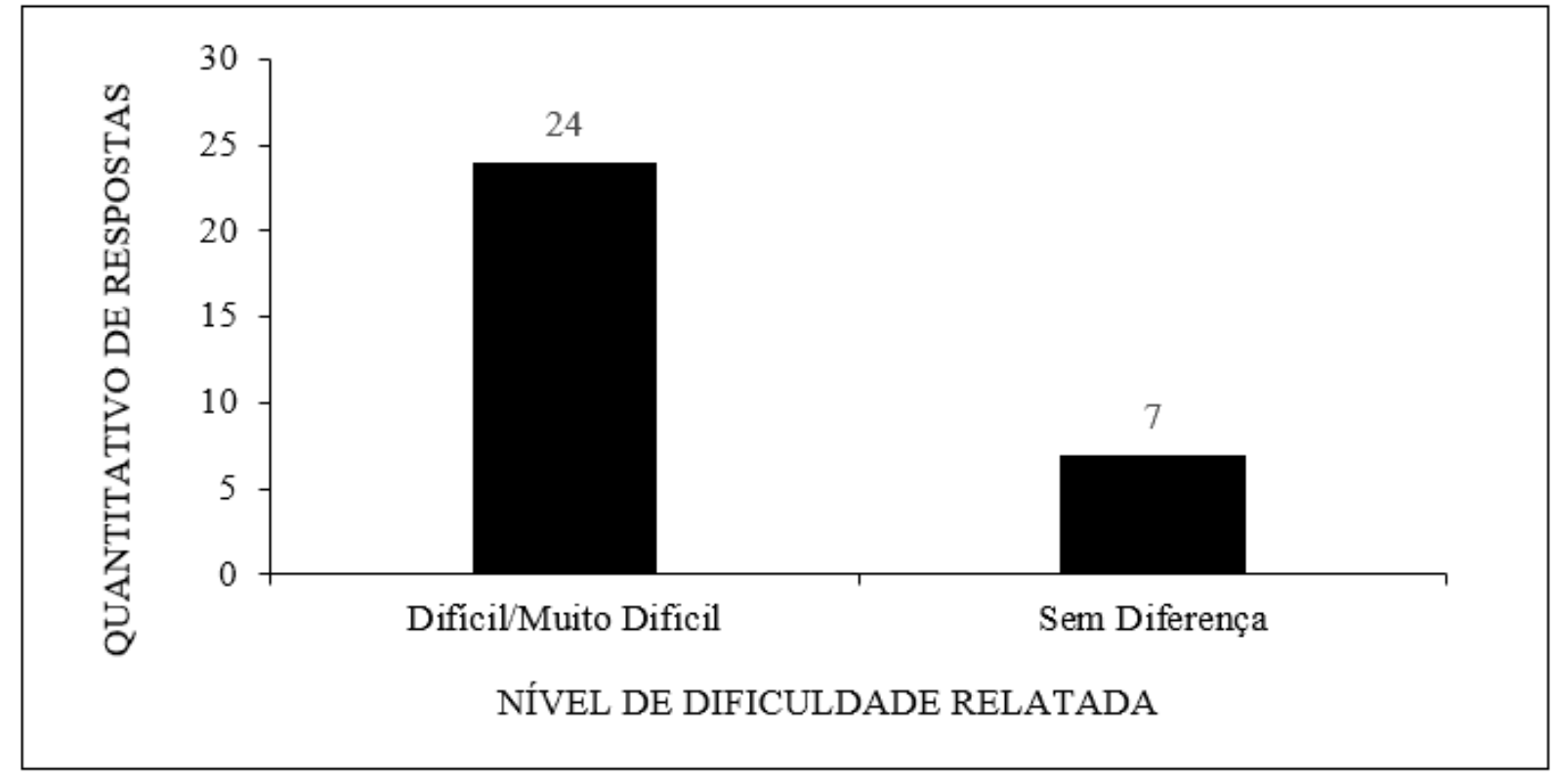

Fonte: Dados próprios.

\section{DISCUSSÃO}

Dos resultados apresentados percebe-se uma predominância de coleta de dados na segunda etapa do método canguru. Considerando que em virtude da pandemia da Covid-19 o Ministério da Saúde (MS) orientou medidas sanitárias o que determinou o ambiente predominante da pesquisa. Dentre as orientações estava a necessidade de triagem dos acompanhantes, bem como afastamento das visitas se sintomático ou contactante por 14 dias após cessar os sintomas, o que por vezes foi motivo da ausência do público da pesquisa em campo (BRASIL, 2020a; BRASIL, 2020b).

A participação materna na pesquisa foi expressivamente maior que a paterna, evidenciando que a presença materna dentro das unidades neonatais é mais prevalente e sua atenção para o RN é integral. Dado este que se compreende de acordo com Marciano e Amaral (2015), quando apresentam que o vínculo materno começa antes do parto, já na ideia de concepção e continuamente na gestação. Importante, então, refletir que esses números também se justificam pelas

RC: 105957

Disponível em: https://www.nucleodoconhecimento.com.br/saude/desafios-de-gestar 
diretrizes da Política de atenção humanizada a qual preconiza a preferência pela participação materna nas práticas, sobretudo pela necessidade de amamentação frequente e cuidados gerais (CARDOSO, et al. 2021) (BRASIL, 2012). Apesar do número reduzido de entrevistas com pais observa-se uma interessante participação masculina no MC apresentando uma mudança no comportamento social onde o cuidado se apresenta de forma mais compartilhada pelos progenitores (CASTOLDI; GONÇALVES; LOPES, 2014).

Em relação ao peso ao nascer dos filhos dos entrevistados, foi evidenciado que grande parte dos $\mathrm{RN}$ da pesquisa apresentavam peso ao nascer acima de $1600 \mathrm{~g}$. O que diverge do esperado, conforme as orientações da política humanizada de atenção ao recém-nascido, pois a mesma orienta a alta da segunda etapa com $1600 \mathrm{~g}$ se observado os demais critérios que consideram a propriedade da mãe e da família em prover os cuidados adequados em casa e o comparecimento as consultas subsequentes e também características antropométricas específicas, como o peso mínimo e ganho de peso nos três dias consecutivos que antecedem a alta.

Assim, sugere-se que ainda que os RNs possuam peso adequado para estarem na terceira etapa do método em suas residências e em acompanhamento ambulatorial, observa-se a necessidade de estarem sob internação, o que permitiu a participação da pesquisa ainda na segunda etapa do $\mathrm{MC}$ o que parece estar relacionado a uma deficiente atuação da primeira etapa do campo de estudo no que tange aos aspectos psicossociais que são essenciais a alta precoce destes pacientes.

No presente estudo a idade predominante das mães entrevistadas é de 18 a 35 anos, com pico de 18-25 anos, ainda este dado diverge da literatura nacional a qual apresenta que idade materna avançada está ligada a prematuridade, seja de forma isolada ou acompanhada das doenças crônicas. No entanto, a variável estudada vai ao encontro de um estudo realizado neste mesmo hospital em 2018, HMML, evidenciando que o contexto da prematuridade neste ambiente há uma possível relação com as gestações em pacientes jovens sugerindo que esse cenário é possível 
pela inexperiência associada a ansiedade destas mães com a gestação (OLIVEIRA et al., 2016; PRAZERES, 2011).

A maioria dos progenitores moram juntos, o que pode corroborar para uma melhora da rede de apoio ao RN, sobretudo na alta hospitalar, com vivência da terceira etapa do método canguru. Conforme Buccini et al. (2011) é tão importante no desenvolvimento e ganho de peso, estes que são dois dos principais objetivos na indicação do Método Canguru (BRASIL, 2012). Silva et al. (2020b) destaca essa relação durante a pandemia da Covid-19, evidenciando que este período propiciou uma empatia nunca antes vista e estreitou vínculos de famílias e casais.

Dessa forma, é possível inferir que a proximidade dos pais é benéfica a vivência da prematuridade e baixo peso, e se fortalece pelo contexto pandêmico.

Outra variável importante avaliada no estudo foi a crença religiosa dos entrevistados, que em sua maioria professam a fé cristã, prática esta que é uma importante aliada como rede de apoio em tempos de sofrimento, haja vista que agregar a fé às recomendações médicas se fortalece a capacidade de superação dos desafios, e, portanto, apresenta melhores resultados quando analisada a saúde holisticamente no contexto biopsicossocial (MARTINS et al., 2021). Em tempo, destaca-se que o presente estudo explora duas destas situações difíceis: a gestação em tempos de Covid-19 e o nascimento de um filho vulnerável pela prematuridade e baixo peso ao nascer (ALMEIDA, 2021; SOUTO; ALBUQUERQUE; PRATA, 2020).

A assistência pré-natal sofreu algumas modificações durante a pandemia visando minimizar os riscos de contaminação do SARS-CoV2 (BRASIL, 2021). Estas medidas foram evidenciadas como desafios da gestação com maior frequência a marcação de consulta foi citada, no entanto observou-se que tal fato não interferiu na redução do número mínimo para um pré-natal adequado segundo o MS em contextos normais aquém de situações como a pandemia da Covid-19. Corrobora para isto os resultados obtidos por Bousquat et al. (2020) que identificam, segundo os gestores de saúde, que na região norte se mantiveram as rotinas de pré-natal em $96,2 \%$ ( $50 \%$ da mesma 
forma e $46,2 \%$ com adaptações) e refere que em $77 \%$ do agendamento de consultas para grupos prioritário foi adaptado. Sugerindo que este desafio se justifica pela mudança na forma de acesso a assistência pré-natal ocasionada pela pandemia da Covid-19 (BOUSQUAT et al., 2020).

Ainda sobre as modificações ocorridas na assistência durante a pandemia da Covid19, foi levantado como adversidade a impossibilidade do acompanhamento do cônjuge durante a gravidez em consultas, exames e parto. O que diverge do esperado dado que as notas técnicas não indicam a ausência dos acompanhantes na assistência pré-natal durante a pandemia (BRASIL, 2020b). Sugere-se que tal desafio existiu principalmente por conta da fragilidade das condições de assistência de saúde existentes antes mesmo da pandemia da Covid-19 no Estado do Amapá, que já apresentavam inadequações estruturais e superlotação (CRUZ; DOS SANTOS, 2021).

É consolidado na literatura a vulnerabilidade das gestantes quanto a questões psíquicas por diversos motivos, que vão desde modificações hormonais, sociais até as violências psicológicas vividas gerando um risco psíquico gestacional (SILVA et al., 2020b). O que corrobora com os resultados obtidos na pesquisa que refletem que a dificuldade de gestar na pandemia foi presente, sobretudo em decorrência da necessidade do isolamento social que viveram, aliado aos constantes pensamentos temerosos quanto ao adoecimento próprio e/ou do bebê durante a pandemia da Covid-19. Dado esse que possui resultados concordantes também com Santana et al. (2021) que evidenciou que a ansiedade e depressão foram sintomas presentes nas gestantes que se submeteram ao isolamento neste mesmo período pandêmico.

Observou-se também que um pequeno número de gestantes demonstraram indiferença no que se refere a experiência da gestação na pandemia o que corrobora com a pesquisa de Da Silva et al. (2021), que apresenta reflexões de uma divergência muito interessante quanto a vivência da pandemia determinando que o bem estar no isolamento social é dependente das diversas variáveis tais como: informações de 
qualidade, condições de moradia bem como ao acesso de práticas esportivas seguras, boa qualidade de sono e alimentação.

\section{CONCLUSÃO}

Diante dos dados apresentados foi possível caracterizar o binômio/trinômio da população em estudo os quais estavam nas vivências da segunda etapa do método canguru. Eram majoritariamente mães como preconizado pelas diretrizes do Método Canguru, além do vínculo já estabelecido pré-parto, com faixa etária predominante entre 18 e 35 anos conforme realidade local, professam uma fé cristã o que fortalece a rede de apoio destes bebês e com os RNs com média de peso ao nascer de 1600 g.

Foi possível inferir que a experiência de gestar em tempos de pandemia, respondendo a questão norteadora do artigo, para a maioria dos pais e mães participantes do método canguru na Maternidade Mãe Luzia em Macapá no Estado do Amapá foi um desafio importante. Sendo identificado que as principais adversidades vivenciadas foram a dificuldade da marcação de consultas o que estava diretamente relacionadas as mudanças na organização do pré-natal nas Unidades Básicas de saúde durante a pandemia; a impossibilidade da participação do cônjuge nas rotinas da gestação, que ocorreu devido a dificuldade dos gestores em manter a segurança da saúde das gestantes diante da precária estrutura no âmbito de saúde no Estado do Amapá; o isolamento social que foi muito relatado pelas gestantes e acompanha a literatura vigente onde a ansiedade e depressão são importantes sequelas neste cenário que deram espaço para o temor da morte e/ou adoecimento pela doença em si mesmo podendo contaminar o RN.

No entanto, foi possível destacar que estas dificuldades não impediram a realização do pré-natal com as metas previstas pelo MS. Além disto, o isolamento social, ainda que desafiador, permitiu um fortalecimento na rede de apoio ao $\mathrm{RN}$ através do fortalecimento de empatia que o período pandêmico proporcionou demonstrado em nosso estudo com a maioria dos progenitores residentes no mesmo lar.

RC: 105957

Disponível em: https://www.nucleodoconhecimento.com.br/saude/desafios-de-gestar 
Emerge-se, portanto, a necessidade de maiores estudos dentro das unidades que adotam o Método Canguru para analisar as peculiaridades vividas por estas famílias, que permitam serem fontes de dados para a construção de normas que mantenham a humanização nestes espaços mesmo em situações adversas. Respeitando a importância do cuidado tanto materno quanto paterno ao RN.

\section{REFERÊNCIAS}

ALMEIDA, Wanessa da Silva de et al. Mudanças nas condições socioeconômicas e de saúde dos brasileiros durante a pandemia de COVID-19. Revista Brasileira de Epidemiologia, v. 23, 2020. DOI: 10.1590/1980-549720200105. Disponível em: https://www.scielo.br/j/rbepid/a/w8HSZbzGgKCDFHmZ6w4gyQv/abstract/?lang=pt. Acesso em: 20 nov. 2021.

ARAGÃO, Regina. De mãe para filha: a transmissão da maternidade. In R. Melgaço (Org.), A ética na atenção ao bebê: psicanálise, saúde e educação. São Paulo: Casa do Psicólogo, 2006.

BEZERRA, Lorena Damasceno Alves et al. Benefícios do contato pele a pele para o recém-nascido. Revista Tendências da Enfermagem Profissional (ReTEP), Fortaleza, v. 8, n. 4, p. 2050-2055, 2016. Disponível em: http://www.corence.org.br/wp-content/uploads/2019/03/BENEF\%C3\%8DCIOS-DO-CONTATO-PELEA-PELE-PARA-O-REC\%C3\%89M-NASCIDO.pdf. Acesso em: 13 nov. 2021.

BRASIL. Ministério da Saúde. Secretaria de Atenção à Saúde. Departamento de Atenção Básica. Atenção ao pré-natal de baixo risco. 318 p.: il. - Série A. Normas e Manuais Técnicos. Cadernos de Atenção Básica, n 32. Brasília: Editora do Ministério da Saúde, 2012.

BRASIL. Ministério da Saúde. Gabinete do Ministro. Portaria oㅡ 693 de 05 de julho de 2000: Norma de Atenção Humanizada do Recém-nascido Baixo Peso. 2000. Disponível em:

RC: 105957

Disponível em: https://www.nucleodoconhecimento.com.br/saude/desafios-de-gestar 
https://bvsms.saude.gov.br/bvs/saudelegis/gm/2000/prt0693_05_07_2000.html. Acesso em: 30 dez. 2021.

BRASIL. Ministério da saúde. Secretaria de Atenção à Saúde. Departamento de Ações Programáticas Estratégicas. Manual da terceira etapa do método canguru na atenção básica. Brasília, Brasília: Ministério da Saúde, 2018. Disponível em: https://bvsms.saude.gov.br/bvs/publicacoes/manual_terceira_etapa_metodo_cangur u.pdf. Acesso em: 30 dez. 2021.

BRASIL. Ministério da Saúde. Atenção às Mulheres. Portal de Boas Práticas em Saúde da Mulher, da Criança e do Adolescente. Manual de Recomendações para a Assistência à Gestante e Puérpera frente à Pandemia de Covid-19. 2021. Disponível em: https://portaldeboaspraticas.iff.fiocruz.br/atencao-mulher/manual-derecomendacoes-para-a-assistencia-a-gestante-e-puerpera-frente-a-pandemia-decovid-19/. Acesso em: 19 nov. 2021.

BRASIL. Ministério da Saúde. Atenção às Mulheres. Portal de Boas Práticas em Saúde da Mulher, da Criança e do Adolescente. RECOMENDAÇÕES PARA O MÉTODO CANGURU DURANTE A PANDEMIA DE COVID-19. 2020a. Disponível em: https://portaldeboaspraticas.iff.fiocruz.br/atencao-recem-nascido/recomendacoespara-o-metodo-canguru-em-tempos-da-pandemia-de-covid-19/. Acesso em: 13 nov. 2021.

BRASIL. Ministério da Saúde. Secretaria de Atenção Primária à Saúde. Nota Técnica no 14/2020-COCAM/CGCIVI/DAPES/SAPS/MS. Atenção à Saúde do Recém-nascido no contexto da Infecção pelo novo Coronavírus (SARS-CoV-2), Ago. $2020 \mathrm{~b}$. Disponivel em: https://portaldeboaspraticas.iff.fiocruz.br/atencao-recemnascido/atenc\%CC\%A7a\%CC\%83o-a-saude-do-recem-nascido-no-contexto-dainfeccao-pelo-novo-coronavirus-sars-cov-2/. Acesso em: 17 nov. 2021.

BUCCINI, Gabriela dos Santos et al. Acompanhamento de recém-nascidos de baixo peso pela atenção básica na perspectiva das Equipes de Saúde da Família. Revista 
Brasileira de Saúde Materno Infantil, v. 11, p. 239-247, 2011. Disponível em: https://www.scielo.br/j/rbsmi/a/PrW4WSZNqGdPtPRYVw5cjmG/?lang=pt. Acesso em: 18 nov. 2021.

BOUSQUAT, Aylene et al. Desafios da Atenção Básica no enfrentamento da pandemia da Covid-19 no SUS. Relatório de Pesquisa. USP, Fiocruz, UFBA, UFPEL, OPAS Brasil. Rede de Pesquisa em Atenção Primária à Saúde da Abrasco. Rio de Janeiro: Rede de Pesquisa em APS Abrasco, 2020. Disponível em: https://redeaps.org.br/2020/11/30/desafios-da-atencao-basica-no-enfrentamentoda-pandemia-da-covid-19-no-sus-resultados-para-o-estado-do-rio-dejaneiro/\#: :text=nov,Pesquisa\%20\%3ADesafios\%20da\%20Aten\%C3\%A7\%C3\%A30\%20B\%C3\%A1sica \%20no\%20Enfrentamento\%20da,da\%20Covid\%2D19\%20no\%20SUS\&text=\%C3\%8 9\%20importante\%20que\%20a\%20reorganiza\%C3\%A7\%C3\%A3o,abordagem\%20fa miliar\%20e\%20abordagem\%20comunit\%C3\%A1ria. Acesso em: 18 jan. 2022.

CARDOSO, Mas et al. O vínculo afetivo entre mãe e recém-nascido, na UTI neonatal. In: XIV Encontro Latino Americano de Iniciação Científica e $X$ Encontro Latino Americano de Pós-Graduação - Universidade do Vale do Paraíba. 2010. Disponível em:

http://www.inicepg.univap.br/cd/INIC_2010/anais/arquivos/RE_0303_0874_01.pdf.

Disponível em: 18 nov. 2021.

CASTOLDI, Luciana; GONÇALVES, Tonantzin Ribeiro; LOPES, Rita de Cássia Sobreira. Envolvimento paterno da gestação ao primeiro ano de vida do bebê. Psicologia em estudo, v. 19, p. 247-259, 2014. DOI: 10.1590/1413-737222105008. Disponível: https://www.scielo.br/j/pe/a/FLjqswwtvXHDGL7v4Khqj4n/?format=html. Acesso em: 16 nov. 2021.

CRUZ, Carlos Corrêa; DOS SANTOS, Kátia Paulino. A humanização do parto no Hospital Maternidade Mãe Luzia, em Macapá-AP. Brazilian Journal of Development, v. 7, n. 2, p. 14557-14571, 2021. Disponível em: RC: 105957 
https://brazilianjournals.com/index.php/BRJD/article/view/24532/19598. Acesso em: 19 jan. 2022.

DA SILVA, Ana Luiza Miranda et al. Os impactos no pré-natal e na saúde mental de gestantes durante a pandemia de COVID-19: uma revisão narrativa. Revista Eletrônica Acervo Científico, v. 34, p. e8633-e8633, 2021. DOI: 10.25248/reac.e8633.2021. Disponível

em: https://acervomais.com.br/index.php/cientifico/article/view/8633. Acesso em: 20 nov. 2021.

DOS SANTOS, Susana Paim; OLIVEIRA, Luciana Mattos Barros. Baixo peso ao nascer e sua relação com obesidade e síndrome metabólica na infância e adolescência. Revista de ciências médicas e biológicas, v. 10, n. 3, p. 329-336, 2011. DOI: 10.9771/cmbio.v10i3.5898. Disponível em: https://repositorio.ufba.br/ri/handle/ri/22885. Acesso em: 13 nov. 2021. (Era SANTOS e OLIVEIRA, 2011)

ESTRELA, Fernanda et al. Gestantes no contexto da pandemia da Covid-19: reflexões e desafios. Physis: Revista de Saúde Coletiva, v. 30, p. e300215, 2020. DOI: 10.1590/S0103-73312020300215. Disponível em: https://www.scielo.br/j/physis/a/zwPkqzafcHbRqyZNxzfrg3g/?lang=pt\&format=pdf. Acesso em: 12 nov. 2021.

MARTINS, Dalila de Alcântara et al. Religiosidade e saúde mental como aspecto da integralidade no cuidado. Revista Brasileira de Enfermagem, v. 75, n.1, 2021. DOI: 10.1590/0034-7167-2020-1011. Disponível em: https://www.scielo.br/j/reben/a/YTKD4sYTBH4Jpxw6gTgyWxS/abstract/?lang=pt. Acesso em: 30 dez. 2021.

OLIVEIRA, Laura Leismann de et al. Fatores maternos e neonatais relacionados à prematuridade. Revista da Escola de Enfermagem da USP, v. 50, p. 382-389, 2016. Fatores maternos e neonatais relacionados à prematuridade. DOI: 10.1590/S0080- 
623420160000400002.

https://www.scielo.br/j/reeusp/a/7MGKxJcY8Ldgf8ynN69LWJk/?lang=pt\&format=pdf. Acesso em: 17 nov. 2021.

OMS. Word Health Organization. Novel Coronavirus (2019-nCoV). [Internet]. 2020. Disponível em: https://www.who.int/docs/default-source/coronaviruse/situationreports/20200130-sitrep-10-ncov.pdf?sfvrsn=d0b2e480_2. Acesso em: 23 nov. 2021.

PRAZERES, Maria Meire Barbosa. Prevalência e fatores de risco associados a prematuridade no hospital maternidade referência do estado do Amapá. 2011. 61 f. Monografia (Especialização) - Curso de Residência Médica, Pediatria, Universidade Federal do Amapá, Macapá, 2011.

RAPHAEL-LEFF, Francesca. 'Spilt Milk': Perinatal Loss and Breakdown edited by Joan Raphael-Leff. Published by the Institute of Psychoanalysis, London, 20. British Journal of Psychotherapy, v. 17, n. 2, p. 261-262, 2000. Disponível em: https://pepweb.org/browse/document/bjp.017.0261a. Acesso em: 30 dez. 2021.

ROMERO, Sandra Leria; CASSINO, Luciana. Saúde mental no cuidado à gestante durante o pré-natal. Revista Brasileira de Ciências da Vida, v. 6, n. 2, p. 1-21, 2018. Disponível

em: http://jornalold.faculdadecienciasdavida.com.br/index.php/RBCV/article/view/560/287 . Acesso em: 10 jul. 2021

SANTANA, Paulo Ricardo Ribeiro et al. A influência do isolamento social decorrente da pandemia da COVID-19 sobre a saúde mental das gestantes: revisão de literatura. Research, Society and Development, v. 10, n. 13, p. e77101321208-e77101321208, 2021. DOI: 10.33448/rsd-v10i13.21208. Disponível em: https://rsdjournal.org/index.php/rsd/article/view/21208. Acesso em: 15 nov. 2021.

SILVA, Isabela Machado da et al. As relações familiares diante da COVID-19: recursos, riscos e implicações para a prática da terapia de casal e família. Pensando 
famílias, Porto Alegre, v. 24, n. 1, p. 12-28, jul. 2020a. Disponível em: https://repositorio.unb.br/handle/10482/40030. Acesso em: 14 nov. 2021.

SILVA, Carlos Eduardo Menezes da et al. Influência das condições de bem-estar domiciliar na prática do isolamento social durante a Pandemia da Covid-19. Journal of Health \& Biological Sciences, v. 8, n. 1, p. 1-7, 2020b. DOI: http://dx.doi.org/10.12662/2317-3076jhbs.v8i1.3410.p1-7.2020. Disponível em: https://periodicos.unichristus.edu.br/jhbs/article/view/3410. Acesso em: 14 nov. 2021.

SILVA, Larissa Távore et al. Gestação e pandemia da COVID-19: Impactos no binômio materno-fetal. Research, Society and Development, v. 10, n. 7, p. e23510716416e23510716416, 2021. DOI: 10.33448/rsd-v10i7.16416. Disponível em: https://rsdjournal.org/index.php/rsd/article/view/16416/14739. Acesso em: 13 nov. 2021.

SOUTO, Sandra Patrícia Arantes do; ALBUQUERQUE, Rosemeire Sartori de; PRATA, Ana Paula. O medo do parto em tempo de pandemia do novo coronavírus. Revista Brasileira de Enfermagem, v. 73, 2020. Disponível em: https://www.scielo.br/j/reben/a/n335kgkbtL7mhFQfnfYHy9K/?format=pdf\&lang=pt. Acesso em: 13 nov. 2021.

VALANSI, Luciana; MORSCH, Denise Streit. O psicólogo como facilitador da interação familiar no ambiente de cuidados intensivos neonatais. Psicologia: ciência e profissão, v. 24, p. 112-119, 2004. Disponível em: https://www.scielo.br/j/pcp/a/Pxpk3zGxwcjSb3mdGZYcvPP/?format=pdf\&lang=pt. Acesso em: 30 dez. 2021.

WERNECK, Guilherme Loureiro; CARVALHO, Marilia Sá. A pandemia de COVID-19 no Brasil: crônica de uma crise sanitária anunciada. Cadernos de Saúde Pública, v. 36, p. e00068820, 2020. DOI: 10.1590/0102-311X00068820. Disponível em: https://www.scielosp.org/article/csp/2020.v36n5/e00068820/pt/. Acesso em: 17 nov. 2021.

RC: 105957

Disponível em: https://www.nucleodoconhecimento.com.br/saude/desafios-de-gestar 
ZHU, $\mathrm{Na}$ et al. A novel coronavirus from patients with pneumonia in China, 2019. New England journal of medicine, n. 382, p.727-733, 2020. DOI: 10.1056/NEJMoa2001017. em:

https://www.nejm.org/doi/full/10.1056/nejmoa2001017. Acesso em: 30 dez. 2021.

Enviado: Janeiro, 2022.

Aprovado: Janeiro, 2022. 